\title{
Lei de terras, imigração e apropriação territorial no Paraná da segunda metade do século xix ${ }^{1}$
}

Alex Sander Sanoto ${ }^{2}$

Resumo: Este artigo tem como interesse discutir o processo de apropriação das terras no Paraná durante o período que se estende entre 1854 e 1889. Mais detidamente, o objetivo é discutir aspectos relacionados à aplicação dos preceitos da Lei de Terras de 1850 para o caso específico da Província do Paraná. Num sentido mais geral, foram abordadas questões relativas ao processo de povoamento do território paranaense, tais como a imigração e o estabelecimento dos limites entre a propriedade pública e privada da terra. Para tanto, foram utilizados documentos produzidos pelo Estado, especialmente as Mensagens enviadas pelos presidentes da província à Assembleia Legislativa. Da mesma forma, também foi realizada análise da produção historiográfica que trata sobre o assunto e sobre o período.

Palavras-chave: Terra, Questão Agrária, Lei de Terras.

Abstract: The present paper intends to discuss the process of appropriation of land in the Province of Paraná in the period between 1854 and 1889. It aims to discuss in closer detail some aspects regarding the extent of enforcement of the clauses prescribed by the Land Act of 1850 concerning the specific case of the Province of Paraná. In a broader sense, this paper also address some questions related to the process of settlement within the territory of Paraná, such

\footnotetext{
${ }^{1}$ Este artigo é resultado de pesquisa de Iniciação Científica que desenvolvi entre os anos de 2011 e 2012 sob orientação do professor Marcio Antônio Both da Silva. O projeto contou com apoio de bolsa de IC modalidade PIBIC/UNIOESTE.

${ }^{2}$ Aluno do $4^{\circ}$ ano do Curso de Graduação em História da Universidade Estadual do Oeste do Paraná.
} 
as those regarding immigration and the setting of boundaries between public and private land. Therefore, this article deals with some documents issued by the State, especially the Messages sent by the presidents of the Province to the Legislative Assembly. Likewise, it offersan analysis aboutsome historiographical works focused onthat subject and historical period.

Keywords: Land, Agrarian Question, Land Act of 1850.

O presente artigo tem por objetivo discutir o modo como ocorreu a ocupação do território do estado do Paraná a partir da segunda metade do século XIX, em especifico dos anos de 1854 à 1889, relacionando esse processo com a Lei n. 601 de 18 de setembro de 1850, mais conhecida com a Lei de Terras. No artigo busco enfatizar algumas outras questões pertinentes a esse processo, como por exemplo: questões imigratórias na província, a situação em que se encontrava a economia do estado paranaense, aspectos relacionados à agricultura, colonização, erva-mate, indígenas, dados demográficos, produção da Província e as diversas transformações e problemas que o ocorrem no Paraná após sua elevação a condição de província em 1853.

A escolha do recorte temporal proposto nesse trabalho, se dá justamente pelo fato do Paraná conseguir sua autonomia provincial em relação a São Paulo e ser elevado a condição de província em 1853 como jáescrito, e também, pelo fato de uma das fontes que servirão de base a análise, ser as mensagens presidenciais enviadas à Assembleia Legislativa provincial, que só passaram a ser escritas no caso do Paraná, a partir do ano de 1854. Quanto ao marco final (1889), sua escolha se 
deu pelo fato de ocorrerem significativas alterações no Brasil, onde, uma delas é a queda do Império e a Proclamação da República. Já nos primeiros anos da Republica, no ano de 1891 em especifico, ocorre a organização de uma nova Constituição, sendo que a partir delaa responsabilidade de legislar sobre as terras passa a ser dos estados.

Para o desenvolvimento desse trabalho, algumas bibliografias relacionadas ao tema foram de grande importância. Uma delas, foram as análises produzidas por José de Souza Martins no livro $O$ cativeiro da terra ${ }^{3}$,queforam de extrema importância para a compreensão do processo de apropriação territorial brasileiro, relacionando no nosso caso, com a província do Paraná, além, de nos mostrar o quanto a Lei de Terras de 1850 teve importância significativa na expansão das relações capitalistas em direção ao campo, cujo resultado mais significativo foi a mercantilizarão do acesso às terras. Outra leitura que contribuiu muito para esse trabalho, foi o livro, Paraná: Ocupação do território, População e Migrações ${ }^{4}$ de Sério Odilon Nadalin, onde, pude conhecer os processos relativos a vinda de imigrantes e o modo como ocorreu a sua fixação, bem como, os motivos que estavam envolvidos na imigração direcionada à Província do Paraná.

No caso do Paraná, pode-se dizer, que seu amadurecimento iniciou-se a partir do século XIX, mais especificamente, a partir da segunda metade. Alguns autores, como por exemplo Sérgio Odilon

\footnotetext{
${ }^{3}$ MARTINS, José de Souza. O Cativeiro da Terra. São Paulo: LECH, 1981.

${ }^{4}$ Nadalin, Sério Odilon. Paraná: Ocupação do território, População e Migrações. Curitiba: SEED, 2001.
} 
Nadalin, demonstram que a vinda do imigrante, principalmente europeu, era uma maneira de preencher os espaços demográficos vazios no mapa, pois, desde do início da colonização o Paraná enfrentava grandes dificuldades em ocupar seu vasto território. Desse modo, Nadalin, destaca que o principal problema que essa província enfrentava, dizia respeito a existência de regiões que não estavam densamente habitadas (ponto de vista que desconsiderava o papel e a presença de indígenasque estavam espalhados por diversas áreas da província e também de lavradores pobres, os quais, com a nova Lei de Terras, dificilmenteconseguiram manter as suas posses). Outra circunstânciaque gerava temores nas autoridades governamentais brasileiras era a possibilidade de uma possível invasão desses territórios por parte dos países vizinhos.Assim, foram frequentes os argumentos para incentivar o desenvolvimento de políticas voltadas a atrair imigrantes para se estabelecerem como produtores agrícolas na província.

Sérgio Nadalin ainda destaca o quanto era evidente que o Paraná estava longe de ser o território que mais recebia imigrantes no período,contudo, a sua presença e movimentação na província era considerável, fato que fica visível ao se levar em conta o número de colônias fundadas. Nestes termos, se da década de 1820 até a de 1850 
foram estabelecidas apenas três colônias no Paraná, desta última data até 1890 , foram 46 o número de colônias criadas ${ }^{5}$.

A relação entre a Lei de Terras e a imigração está diretamente vinculada aos fatores que caracterizavam aquele momento histórico. Ocupa lugar de destaque, neste sentido, a emergente possibilidade de emancipação dos escravos, principalmente os problemas relativos à necessidade de existência de um contingente de pessoas dispostas a trabalhar em substituição da mão de obra cativa. Portanto, era necessário limitar o acesso dessas pessoas a terra. Assim,

a Lei de Terras instituiu no Brasil a terra como mercadoria e permitiu a vinda de imigrantes para promover a grande e a pequena lavoura [...]. E, ao impedir que desde o início esses camponeses pudessem se tornar proprietários, reafirmava o que deles se esperava: colonos morigerados e laboriosos como força de trabalho para as propriedades agrícolas do Estado ou Particulares. Portanto, a Lei de Terras, ao dificultar o acesso à propriedade ao conjunto da população campesina, ao mesmo tempo colocava este coletivo aos ditames do capital ${ }^{6}$.

Um dos principais fundamentos da política imigratória desenvolvida pelo Império foi o de ocupar espaços considerados pouco povoados, especialmente nas regiões que faziam fronteira com outras

${ }^{5}$ Dados coletados em: MACHADO, Brasil Pinheiro; BALHANA, Altiva Pilatti; WESTPHALEN, Cecília Maria. História do Paraná. Curitiba: Paraná Cultural, 1969, p. 164-167.

6 SANTOS, Carlos Roberto Antunes dos. Coleção história do Paraná: vida material e vida econômica. Curitiba: SEED, 2001. 
nações e corriam risco iminente de serem conquistadaspelas nações vizinhas, como é o caso do Rio Grande do Sul, Santa Catarina e Paraná. Contudo, mesmo diante do aumento no número de estrangeiros que entraram no Brasil a partir de 1850 , o movimento de imigrantes em direção as terras do Paraná ainda era pequeno se comparado com outras províncias - as do sudeste especialmente. ${ }^{7}$

Já na primeira mensagem enviada à Assembleia legislativa, escrita pelo presidente da província Theofilo Ribeiro Resende em 1854, é possível perceber a vinda do imigrante Europeu para esta província, as dificuldades de adaptação em nossas terras, principalmente por se tratar de outro clima, tendo como resultado, grandes problemas de saúde, que foi um dos assuntos abordados durante todo o período, devido a grandes febres que surgiam com o tempo em determinadas regiões. Por meio desta mesma mensagem, é possível perceberas dificuldades e precariedade em que se encontrava a província,pois existiam poucas estradas, e as existentes se encontravam em péssimas condições, não havia hospitais, e a primeira mensagem já deixa bem visível a falta de médicos.

Outra situação que era apresentada como um problema para província é a presença de indígenas, nas mensagens eles são tratados como "selvagens e ladrões". Nos primeiros anos da província foram quatro grandes aldeamentos, sendo eles localizados nos municípios de

${ }^{7}$ Nadalin, Sério Odilon. Paraná: Ocupação do território, População e Migrações. Curitiba: SEED, 2001 
Palmas, Guarapuava, Tibagi e Jatahy. Segundo os presidentes, os índios causavam um enorme problema, por seus ataques as fazendas, pois geralmente praticavam saques e em algumas vezes deixavam feridos. E, na grande maioria dos casos, esses problemas ocorriam em fazendas próximas aos aldeamentos.

$\mathrm{Na}$ maioria das mensagens, uma possível solução a questão indígena é apresentada a partir do desenvolvimento e expansão da catequese, assim, partia-se do pressuposto de que os ensinamentos adequados pudessem resolver os conflitos existentes entre indígenas e os povoadores.

Nesse sentido, observamos um trecho de um relatório enviado à Assembleia Legislativa pelo administrador da província Rodrigo Menezes em 1879:

No intuito de evitar conflictos, cuja consequecias seriam para lamentar, dirigi-me ao governo imperial solicitando autorisação para mandar medir uma área de terrno devoluto para a collocação dos indios e para arbitrar a gratificação de $20 \$ 000$ mensaes a cada um dos caciques dos pontos alluditos, investindo-os do caracter de director.

Concedida a autorisação por aviso de 22 de Agosto do annoproximo passado, expedi ordem ao juiz commissario do municipio de Guarapuava para proceder a escolha de teros apropriados áquelle 
mister, e a medição em um perimetro para ser em commum habitados pelos indios. ${ }^{8}$

Através de um outro trecho do relatório do presidente Alfredo Taunay de1886, observamos mais nitidamente o quanto o processo de catequização era importante para a Paraná, do ponto de vista dos dirigentes desta província. No seguinte trecho: "São todos mansos e ordeiros, de modo que hoje póde-se viajar e habitar em completo sossegoaquella importante região, tanto que nenhum facto criminoso notável, commetido pelos indios, registra a estatistica de taes lugares"9 Mais adiante no mesmo relatório parágrafos a baixo, o presidente registra: "attesta d'um modo animador a indole pacifica do indio, quando catechisado". Podemos perceber a partir das breves citações, a preocupação justamente na catequização como meio de se "amansar" esses índios e assim não ter problema com esses indivíduos. Pois, de primeiro momento, esses sujeitos são marginalizados, representados como invasores de fazendas que agem de forma violenta, mas, que em um segundo momento, que se dá após a catequização, esses índios deixam de ser "selvagens e violentos". Segundo os relatos presentes nas mensagens, após a catequização o número de casos de invasões de

${ }^{8}$ MENEZES, Rodrigo Octavio de Oliveira. Relatório apresentado A' Assembléia Legislativa Provincial do Paranã no dia 31 de março de 1879. Curitiba: Tipografia Paranaense, 1879. p.76

9 TAUNAY, Alfredo Descragnolle. Exposição da administração da província do Paraná ao vice-presidente em 3 de maio de 1886. Curitiba: Tipografia Paranaense, 1886. p. 103 
fazendas reduz consideravelmente $\mathrm{e}$ as regiões próximas de aldeamentos passam a apresentar pouco perigo aos colonizadores.

A partir da segunda mensagem, escrita pelo presidente da província Zacarias de Goes Vasconcellos em 1855, já é possível notar a presença e importância dos escravos africanos na Província, os quais geralmente vinham de São Paulo, para trabalhar na abertura de algumas matas no Paraná. Ainda na década de 1850, as mensagens já mostram o surgimento de diversas vilas, como Castro, Ponta Grossa, Morretes, Palmas, Guarapuava, Antonina e Campo Largo.

Se observarmos as primeiras mensagens provinciais, notamos que todas elas abordam o assunto da imigração europeia, assim como na mensagem escrita pelo presidenteda província do Paraná Henrique de Beaurepaire Rehan em 1856. Na mensagem, consta o seguinte trecho: "uma das ideias, que mais prende a atenção pública no Brasil, é certamente a da colonização. Os meios porém até agora empregados, para realizá-la, nem sempre tem produzido os mais vantajosos resultados"10 $^{10}$. Esse trecho mostra que nos primeiros anos do Paraná enquanto Província, não foi possível realizar a vinda de um grande número de imigrantes, pelo menos, não na proporção esperada ou necessária aos olhos das autoridades governamentais, confirmando ainda o que já havíamos dito. Em outras passagens, Rehan mostra que os poucos imigrantes que para essa terra vieram, foram bem recebidos,

10 REHAN, Henrique de Beaurepaire. Relatório apresentado $A^{\prime}$ Assembléia Legislativa Provincial do Paranã no dia 1 de março de 1856. Curitiba: Tipografia Paranaense, 1856. p.38 
tiveram trabalho bem pago, e comida de fácil acesso. Interpretação que, por seu turno, precisa ser questionada, pois a produção bibliográfica, antes citada, que se preocupou em analisar a situação vivida pelos imigrantes quando de sua chegada ao Brasil, tem demonstrado que suas condições de vida e recebimento não eram as melhores.

A respeito da imigração ainda, o presidente da Província de 1860, José Francisco Cardoso, escreveu o seguinte:

Desde que o governo imperial e o país se empenharam com afinco na repressão do ilícito tráfico de escravos, e que consequentemente foram escasseando os braços, que nos forneciam semelhante comércio, as visitas de nossos labradores volveram-se para a emigração estrangeira, como a única esperança que lhes restava, contra a decadência da produção agrícola.

Entre dois sistemas reconhecidos para facilitar a vinda de colonos, é sem contestação preferível da emigração espontânea: a lei de 18 de setembro de 1850 assim o visou, ordenando a demarcação dos terrenos do modo a extremar o domínio público do particular. ${ }^{11}$

Neste trecho, o presidente demonstra a relação prática existente entre a Lei de Terras de 1850 e a imigração, processos detidamente estudados por José de Souza Marins em seu livro antes citado. Neste

11 CARDOSO, José Franciso. Relatório apresentado A' Assembléia Legislativa Provincial do Paranã no dia $1^{\circ}$ de março de 1860. Curitiba: Tipografia Paranaense, 1860. p. 60 
sentido, é importante sublinhar a intima ligação entre a defesa dos interesses dos grandes possuidores de terras, o processo de substituição da mão de obra escrava pela mão de obra livre e o estabelecimento da propriedade privada da terra não só no Paraná, mas no Brasil como um todo.

Neste sentido, José de Souza Martins destaca o aumento na entrada de imigrantes europeus no Brasil a partir de 1850. Embora este fenômeno estivesse mais presente nas províncias do sudeste do Brasil, onde o trabalho cativo era mais presente do que nas províncias do sul, cabe registrar que a necessidade dessa substituição levou a elaboração da Lei de Terras de 1850, a qual valia para todo o Brasil e não só para as províncias do sudeste. Martins também problematiza o quanto o trabalho livre teve significados distintos para os principais sujeitos envolvidos nesse processo. Onde, para os escravos, o trabalho livre significava que agora ele seria livre e poderia vender a sua força de trabalho, porém, quanto ao acesso a terra seria difícil, pois a lei de 1850 buscava impor limites ao acesso de apropriação, e uma dessas formas era que o acesso a terra só poderia se dar através da compra. Dessa forma, a Lei de 1850 também dificultou o acesso a terra aos imigrantes e as pessoas que não tinham condições financeiraspara pagar pelos espaços territoriais que ocupavam. Como já dito, restava-lhes, portanto, a opção de vender sua força de trabalho para tentar sobreviver. Nestes termos, a defesa da imigração é uma constante ao longo das mensagens, e, geralmente, ela adota o seguinte conteúdo: 
Abusaria de vossa ilustração se me ocupasse de demonstrar-vos a necessidade de promoverdes a emigração de colonos morigerados e laboriosos, que, conhecedores de processos mais acabados, e habituados ao uso de instrumentos mais vantajosos, ao maneio e cultura das terras, se empreguem nos vastos campos que possue a província, e cuja prodigiosa fertilidade abrange todo o gênero de produção agricola, limitarei pois indicar-vos o meio, que me parece mais adaptavel, para consseção de tão almejado bem. ${ }^{12}$

Seguindo adiante, ainda no mesmo relatório, o Presidente da Província do Paraná, Francisco Liberato Mattos, nos traz mais um trecho pertinente ao assunto:

é para lamentar que esta província, cujos terrenos produzem com abundância, a mandioca, o arroz, o café, a cana, o fumo, o milho, o centeio, a cevada, o trigo e todos os gêneros alimentícios, compensando tão prodigiosamente o trabalho do agricultor, receba da marinha e por preços tão exagerados a mor parte daqueles gêneros ${ }^{13}$.

Nesses dois trechos de relatório, além da importância de produtos de gêneros alimentícios, fica evidente o quanto as terras do Paraná eram férteis e necessitavam urgentemente de pessoas, que além

\footnotetext{
${ }^{12}$ MATTOS, Francisco Liberato de. Relatório do Presidente da provincia do Paranã na abertura da assembleia lgislativa provincial em 7 de Janeiro de 1858.Curitiba: Tipografia Paranaense, 1858. p. 21

${ }^{13}$ Ibidem.
} 
de ocupar essas terras, saibam manejar, para que possam produzir com habilidade e rapidez. Porém, esses projetos promovidos pela província não levavam em conta o papel dos indivíduos que já estavam fixados nessas terras, que em sua maioria eram habitadas por indígenas e lavradores pobres. Desse modo, a elite político-econômica que administrava a província do Paraná, que estava envolvida diretamente na execução dos projetos de colonização, tentava modificar e dar novos padrões à agricultura paranaense e tudo aquilo que não atendesse aos seus projetos deveria ser modificado. Para tanto elegia que grupos seriam mais adequados para realizar tal tarefa:

A tal respeito, o Exm. Snr. Dr. Tannay fez largas considerações sobre a colocação dos imigrantes, e declarou que desejava principalmente ver o alemão, e o habitante do norte da Europa, atraídos pela possibilidade de cultivarem o trigo, centeio, aveia e quando muito a vinha, e não fascinados pelo café e outros produtos intertropicais, que lhes trairão grandes vicissitudes, pela diferença de vida a que tinham de sujeitar-se. ${ }^{14}$

Nesse trecho retirado de uma mensagem de 1886, podemos observar que havia uma certa preferência de quais sujeitos deveriam se estabelecer no Paraná. Nesse caso, imigrantes alemães, por ter mais experiência em um determinado cultivo. $\mathrm{O}$ grande problema nisso tudo, e que não é citado nos relatórios, é o modo como isso se dava na

14 TAUNAY, Alfredo Descragnolle. Exposição da administração da província do Paraná ao vice-presidente em 3 de maio de 1886. Curitiba: Tipografia Paranaense, 1886. p. 102 
prática, ou seja, a vinda do imigrante para essa província e a conquista do seu pedaço de terra e de seu espaço para cultivo.

Outro trecho que nos possibilita fazer uma análise a respeito da posse da terra e que envolve diretamente a Lei de 1850 e o projeto imigratório, diz o seguinte:

A Lei de Terras consagrava aquilo que não existia plenamente: a terra como equivalente de capital, como renda territorial capitalizada. Ao mesmo tempo, torna-se explicito, enfatizado e socialmente reconhecido que o trabalho é o fundador da riqueza, que o trabalho é a virtude essencial do trabalhador. Para se ter acesso a propriedade, isto é, a riqueza, é preciso trabalhar e poupar. ${ }^{15}$

Seguindo a perspectiva de Martins, outra mudança que está diretamente envolvida nesse contexto, são os fatores que dão significado de riqueza e status aos sujeitos, além, do que seria significado de privilegio e valor. Até 1850 o escravo é que era o fator de produção e de valor. Contudo, a partir da lei de terras ocorre uma mudança, pois a terra passa a ser o fator de riqueza. Além disso, o trabalho que era considerado coisa de escravo passa por um processo de valorização. Essas mudanças são visíveis nos projetos imigratórios e a busca por imigrantes que fossem trabalhadores e morigerados vinculase diretamente a esses fatores.

${ }^{15}$ MARTINS, José de Souza. O Cativeiro da Terra. São Paulo: LECH, 1981. p. 147. 
O presidente da província Joaquim d' Almeida Faria Sobrinho de 1888, relata como em alguns períodos foi insignificante a entrada de imigrantes no Paraná em relação a outras províncias dos Sul. Além disso, o número de imigrantes era bastante variável, por exemplo, em 1888 chegaram ao Paraná 383 imigrantes, em 1875 número ficou na casa dos 308 imigrantes, já em 1887 o número subiu para cerca de 800 imigrantes. $\mathrm{O}$ presidente também destaca a grande diferença existente em relação ao estado de São Paulo, pois, no mesmo ano que entraram 383 imigrantes no Paraná, São Paulo registrava a entrada de mais de 23.000 europeus ${ }^{16}$.

Alfredo Taunay, em uma exposição da administração $a$ província do Paraná, já citado aqui, nos mostra o modo como ele observava a questão da produção na província no ano de 1886 no seguinte trecho:

A grande questão é, a par da bem entendida economia, buscar a aumentar as fontes de receita. $\mathrm{Na}$ imigração, no desenvolvimento da indústria de pinho, que pode no futuro dar imensos resultados, no aperfeiçoamento da fabricação do mate, na exposição das poderosas forças vivas da Província, vejo largos horizontes abertas as suas esperanças e ambições. ${ }^{17}$

\footnotetext{
${ }^{16} \mathrm{Idem}$

17 TAUNAY, Alfredo Descragnolle. Exposição da administração da província do Paraná ao vice-presidente em 3 de maio de 1886. Curitiba: Tipografia Paranaense, 1886. p. 121
} 
Podemos perceber através desse pequeno trecho, algumas ponderações sobre pontos já esboçados aqui, mas que talvez nos permite observar com mais clareza. Pois, podemos perceber nesse trecho, algumas preocupações com a economia, que inclusive envolve consideravelmente a produção da erva mate e o aperfeiçoamento do seu processo, até mesmo a questão da imigração.

Desse modo, fica evidente a importância de conhecer os processos característicos da segunda metade do século XIX para compreender a história, pois, foi durante esse período que ocorreu a ocupação de parte do território geográfico da província, por meio da vinda dos imigrantes europeus, especialmente entre os anos de 1829 e 1911, quando chegaram cerca de 83.012 imigrantes. ${ }^{18}$ Este crescimento populacional, também significou o aumento nos conflitos relativos a ocupação do território, principalmente se levarmos em conta que este contingente populacional se estabeleceu em áreas que historicamente eram alvos de disputas, seja por parte de grandes ou pequenos possuidores de terras.

Alguns estudos sobrea Província do Paraná, também nos mostram que o Paraná possuía outras fontes econômicas além das já citadas, como por exemplo, a criação e comércio de muares, o aluguel de pastagens para os tropeiros fazerem pausas para descanso durante suas viagens, que geralmente percorriam o trecho entre São Paulo e Rio Grande do Sul, a comercialização do gado, que tinha um peso

${ }^{18}$ Sério Odilon Nadalin. Idem, op, cit, p. 78. 
significativo na economia de todo o Sul do Brasil. Já como produtos destinados a comercialização e a exportação, a madeira e a produção de erva mate recebiam lugar de destaque. Contudo, cabe registrar que a erva mate sempre sofreu grandes alterações. Segundo Carlos Roberto Antunes dos Santos, tais variações podem ser verificadas em 4 momentos distintos: o piso (1842 a 1851), crescimento ou prosperidade (1852 a 1856), o auge (1856 a 1857), queda ou crise (1858 em diante). ${ }^{19}$

Seguindo as perspectivas de Carlos Santos, podemos compreender o ciclo de comercialização da erva-mate, onde o "piso" significa o início da sua produção, passando por um crescimento importante em 1852 e se deparando com a primeira crise em 1858, vindo a se estabilizar no mercado em 1869.

Analisando os relatórios, observamos que também são citados dados sobre os rendimentos da província, bem como os principais produtos a gerarem tais divisas econômicas. Segue, como exemplo, os números apresentados pelo presidente da Província José Francisco Cardoso em 1860 a respeito da renda geral da província desde sua fundação:

19 SANTOS, Carlos Roberto Antunes dos. Vida material e econômica. Curitiba: SEED,p. 45. 
TABELA 1: Renda geral da Província do Paraná desde sua fundação até $1859^{20}$

\begin{tabular}{|l|l|}
\hline Ano & Renda \\
\hline 1853 a 1854 & $89: 344$ U074 \\
\hline 1854 a 1855 & $116: 706$ U589 \\
\hline 1855 a 1856 & $188: 489$ U812 \\
\hline 1856 a 1857 & $277: 102$ U089 \\
\hline 1957 a 1858 & $305: 756 U 535$ \\
\hline 1858 a 1859 & $210: 249$ U529 \\
\hline
\end{tabular}

No Relatório da província elaborado pelo presidente Joaquim d'Almeida Faria Sobrinho no ano de 1888, constam os seguintes números sobre a produção de erva mate:

${ }^{20}$ Tabela apresentada no Relatório da província emitida pelo presidente José Francisco Cardoso no dia 1 de março de 1860, p. 8 
TABELA 2: Produção de erva-mate no Paraná entre 1867 e $1887^{21}$

\begin{tabular}{|c|c|}
\hline ANOS & QUANTIDADE \\
\hline 1867 & 12.462 .217 quilos líquidos \\
\hline 1868 & 12.813 .323 quilos líquidos \\
\hline 1869 & 13.365 .559 quilos líquidos \\
\hline 1870 & 14.282 .085 quilos líquidos \\
\hline 1871 & 13.714 .260 quilos líquidos \\
\hline 1872 & 16.632 .502 quilos líquidos \\
\hline 1873 & 13.442 .407 quilos líquidos \\
\hline 1874 & 11.706 .319 quilos líquidos \\
\hline 1875 & 11.559 .116 quilos líquidos \\
\hline 1876 & 12.702 .371 quilos líquidos \\
\hline 1877 & 13.209 .020 quilos líquidos \\
\hline 1878 & 12.971 .418 quilos líquidos \\
\hline 1879 & 14.087 .730 quilos líquidos \\
\hline 1880 & 12.669 .187 quilos líquidos \\
\hline 1881 & 12.949 .917 quilos líquidos \\
\hline 1882 & 15.167 .249 quilos líquidos \\
\hline 1883 & 15.300 .731 quilos líquidos \\
\hline 1884 & 14.524 .420 quilos líquidos \\
\hline 1885 & 14.502 .504 quilos líquidos \\
\hline 1886 & 14.735 .630 quilos líquidos \\
\hline 1887 & 18.880 .000 quilos líquidos \\
\hline
\end{tabular}

${ }^{21}$ Tabela apresentada no Relatório da província emitida pelo presidente Joaquim d'Almeida Faria Sobrinho no dia 29 de dezembro de 1888, p. 35 
A partir da análise das duas tabelas apresentadas pelos presidentes da província e também os dados apresentados por Carlos Roberto, podemos ter algumas impressões sobre os autos e baixos das economia da província no período aqui sob análise (1854-1889).

Como todo processo histórico, a colonização e o povoamento das terras da Província do Paraná são marcados por vários momentos. Assim, a relevância em realizar estas análises referentes a esse assunto são de estrema importância, pois, podemos perceber quem eram os sujeitos envolvidos no processo, bem como quem estava a sua frente, e ao mesmo tempo, observar que houveram sujeitos que acabaram ficando as margens desse processo,bem como, o modo como a Lei de 1850 veio a favorecer determinados grupos sociais e dificultar ainda mais o acesso a terra ao pequeno camponês, ao trabalhador livre, e aos imigrantes que vinham para cá acreditando que conseguiriam seu pedaço de terra para praticar seu cultivo. Percebe-se também como os projetos do Estado, ligado com as elites político-econômicas, eram elaborados visando interesses específicos, no caso aqui analisado mobilizar mão de obra barata e realizar a valorização das terras.

Este estudo também pode nos ajudar a ter uma maior compreensão de problemas sociais que estão presentes e são definidores da realidade dos dias de hoje. Problemas estes, que estão relacionados com a questão agrária brasileira, a qual teve sua origem noperíodo colonial, mas que passa a tomar contornos mais nítidos a partir da 
segunda metade do século XIX, com a promulgação da Lei de Terras em 1850.

\section{Fontes:}

CARDOSO, José Francisco. Relatório apresentado a assembléa Legislativa da provincia do Paranã na abertura da primeira sessão da quarta legislação no dia 1 de março de 1860. Curitiba: Tipografia Paranaense, 1960.

MATTOS, Francisco Liberato de. Relatório de Presidente Francisco Liberato Mattos, apresentado na abertura da assembleia Legislativa Provincial, em 07 de janeiro de 1858. Curitiba: Tipografia Paranaense, 1858.

MENEZES, Rodrigo Octavio de Oliveira. Relatório apresentado $A^{\prime}$ Assembléia Legislativa Provincial do Paranã no dia 31 de março de 1879. Curitiba: Tipografia Paranaense, 1879.

NOGUEIRA, Antonio Barbosa Gomes. Relatório apresentado a Assembleia da provincia do Paranã na abertura da primeira sessão da quinta legislatura no dia 15 de fevereiro de 1862. Curitiba: Tipografia Paranaense, 1962.

REHAN, Henrique de Beaurepaire. Relatório apresentado $A^{\prime}$ Assembléia Legislativa Provincial do Paranã no dia 1 de março de 
1856. Curitiba: Tipografia Paranaense, 1856. Curitiba: Tipografia Paranaense, 1856.

RESENDE, TheofiloRibeirode. Relatório do estado do Paranã apresentado ao vice-presidente Henrique de BeaurepaireRohan por occcasião de lhe entregar a adiministração da mesa provincia em 6 de setembro de 1854. Curitiba: Tipografia Paranaense, 1854

SOBRINHO, Joaquim d'Almeida Faria Sobrinho. Relatório apresentado A' Assembléia Legislativa Provincial do Paranã no ano de 1888. Curitiba: Tipografia Paranaense, 1888. Curitiba: Tipografia Paranaense, 1888.

TAUNAY, Alfredo Descragnolle. Exposição da administração da província do Paraná ao vice-presidente em 3 de maio de 1886. Curitiba: Tipografia Paranaense, 1886.

\section{Referências:}

MARTINS, José de Souza. O Cativeiro da Terra. São Paulo: LECH, 1981.

NADALIN, Sério Odilon. Paraná: Ocupação do território, População e Migrações. Curitiba: SEED, 2001.

SANTOS, Carlos Roberto Antunes dos. Vida material e econômica. Curitiba: SEED, 2001. 